\title{
Primary cavernous hemangioma of the thyroid gland
}

\author{
Devika Gupta, Sunita Kakkar, Pooja Gupta, Vandana Rana
}

\section{To the Editor,}

Hemangiomas are benign vascular neoplasms that have a characteristic clinical course marked by early proliferation and spontaneous involution. They occur in a number of organs including skin, lips, liver, colon, brain, etc. $[1,2]$.

Primary thyroid hemangiomas are extremely uncommon with only a few cases have been reported [3]. We report a case of cavernous hemangioma presenting as solitary nodule thyroid.

A 49-year-old male presented with one year history of slowly enlarging swelling on left side of the neck. There was no history of any associated pain, voice change or dyspnea. There was no history of any trauma or previous fine needle aspiration cytology (FNAC). There was no family history of thyroid disease.

Local examination revealed an approximately $3 \times 2.5 \mathrm{~cm}$ nontender swelling in front and left side of cricoid cartilage. The swelling was firm to hard with well defined margins and it moved with deglutition.

Serum thyroid stimulating hormone was $3.8 \mathrm{mIU} / \mathrm{L}$ (normal range $0.4-4.0 \mathrm{mIU} / \mathrm{L}$ ) and free $\mathrm{T} 4$ was $9 \mathrm{pmol} / \mathrm{L}$

Devika Gupta1', Sunita Kakkar², Pooja Gupta ${ }^{3}$, Vandana Rana $^{4}$

Affiliations: ${ }^{1} \mathrm{MD}$, Pathology, Assistant Professor, Armed Forces Medical College, Department of Pathology and Laboratory Science, Command Hospital, Pune, India; ${ }^{2} \mathrm{MD}$, Pathology and OncoPatholgy, Professor, Armed Forces Medical College, Department of Pathology and Laboratory Science, Command Hospital, Pune, India; ${ }^{3} \mathrm{MD}$, RadioDiagnosis, Department of Radiodiagnosis and Imaging, Armed Forces Medical College, Pune, India; ${ }^{4} \mathrm{MD}$, Pathology, Department of Pathology and Laboratory Science, Command Hospital, Pune, India.

Corresponding Author: Devika Gupta, MD, Pathology, Assistant Professor, Armed Forces Medical College, Department of Pathology and Laboratory Science, Command Hospital, Pune -411040, India; Ph: 9158984335; Email: devikalives5h@gmail.com

Received: 14 March 2013

Accepted: 10 May 2013

Published: 01 September 2013 (normal range 10.3-24.5 pmol/L). These hormonal levels were normal and no antithyroid antibodies were detected.

Thyroid ultrasonography revealed a $2.5 \times 2.8 \mathrm{~cm}$ isoechoic lesion in the left lobe of thyroid with a hypoechoic rim and a prominent vessel having arterial flow in its superior aspect (Figure 1). Ultrasonography did not show any areas of calcification or cervical lymph nodes. Right lobe of thyroid was normal.

The FNAC of the mass was attempted thrice but was inconclusive as only blood was aspirated. Patient underwent left hemithyroidectomy. Gross examination of the cut surface of the specimen revealed a well circumscribed nodular lesion measuring $2.5 \times 2.8 \mathrm{~cm}$. It appeared cystic and hemorrhagic in appearance.

Histological examination of the tumor confirmed a cavernous hemangioma. There were multiple, dilated, irregular anastomosing vascular channels of varying sizes. These vascular spaces were lined by bland endothelial cells. Amidst these were noted an occasional entrapped thyroid follicle (Figure 2A-B). The patient was discharged from the hospital after five days with no signs of complication.

In most cases, a cavernous hemangioma of the thyroid gland represents a secondary hemangioma occurring due to previous FNAC. These are formed due to vascular proliferation in organized hematoma following FNAC $[4,5]$. Organization of the hematoma generally results in complete resolution, but it can give rise to vascular and fibroblastic proliferative changes that resemble a cavernous hemangioma. This is defined as secondary hemangioma.

Primary hemangioma is a developmental anomaly resulting from inability of angioblastic mesenchyma to form canals [6]. Preoperative diagnosis of hemangioma of the thyroid is difficult since there are no pathognomic features on FNAC, ultrasonography or computed tomography scans. The presence of heterogenous signal intensity and serpentine pattern on magnetic resonance imaging (MRI) scan is considered highly suggestive of cavernous hemangioma [7]. In patients with a thyroid swelling who have a cold nodule on thyroid scan and only blood is aspirated on repeated FNACs, Technetium-99m erythrocyte blood pool imaging may be performed to diagnose hemangioma. Little or no increased activity is 
seen soon after injecting the label, and this appearance of poor perfusion and slow filling of the tumor is characteristic of cavernous hemangioma. Hemangioma should be considered in the diagnosis of any pulsatile mass involving the thyroid gland. Diagnosis before surgery is difficult and the definite diagnosis relies on histological findings of surgical specimen.

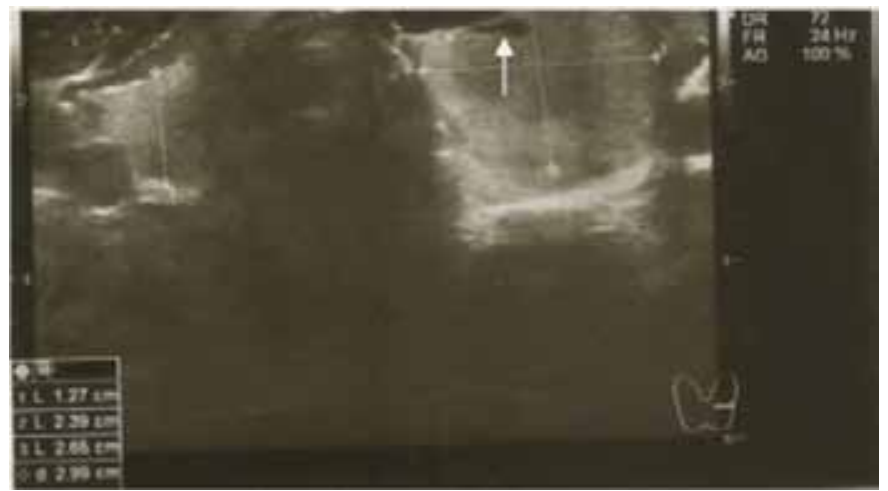

Figure 1: Ultrasonographic image of the left lobe of thyroid showing $2.4 \times 2.6 \mathrm{~cm}$ well defined isoechoic lesion with hypoechoic rim and a large prominent vessel within having arterial flow (marked with arrow).

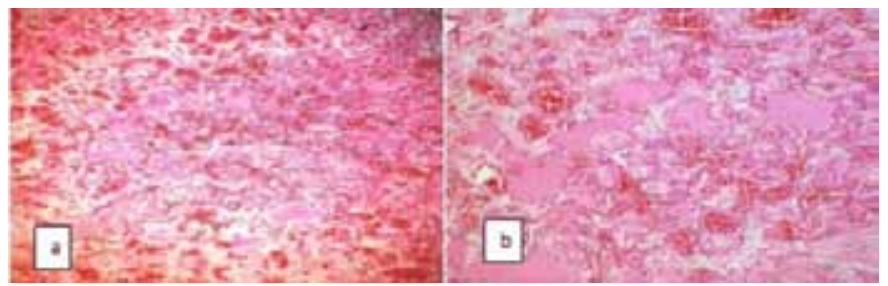

Figure 2: (A) The thyroid nodule shows dilated, congested varying sized anastomosing vascular channels (H\&E stain, x20), (B) A few scattered colloid filled thyroid follicles amidst the vascular channels (H\&E stain, $\mathrm{x} 40$ ).

$* * * * * * * * *$

Gupta D, Kakkar S, Gupta P, Rana V. Primary cavernous hemangioma of the thyroid gland. International Journal of Case Reports and Images 2013;4(9):524-526.

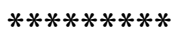

doi:10.5348/ijcri-2013-09-371-LE-15
Sunita Kakkar - Acquisition of data, Drafting the article, Revising it critically for important intellectual content, Final approval of the version to be published

Pooja Gupta - Acquisition of data, Drafting the article, Revising it critically for important intellectual content, Final approval of the version to be published

Vandana Rana - Acquisition of data, Drafting the article, Revising it critically for important intellectual content, Final approval of the version to be published

\section{Guarantor}

The corresponding author is the guarantor of submission.

\section{Conflict of Interest}

Authors declare no conflict of interest.

\section{Copyright}

(C) Devika Gupta et al. 2013; This article is distributed under the terms of Creative Commons attribution 3.0 License which permits unrestricted use, distribution and reproduction in any means provided the original authors and original publisher are properly credited. (Please see www.ijcasereportsandimages.com/copyright-policy.php for more information.)

\section{REFERENCES}

1. Kano M, Kameyama K, Hosoda Y, Sugino K, Ito K. A cavernous haemangioma of the thyroid gland. $\mathrm{J}$ Laryngol Otol 2005 Oct;119(10):828-30.

2. Ríos A, Rodríguez JM, Martínez E, Parrilla P. Cavernous hemangioma of the thyroid. Thyroid 2001 Mar;11(3):279-80.

3. Kumamoto K, Sugano K, Hoshino M, Utsumi Y, Suzuki S, Takenoshita S. Cavernous hemangioma of the thyroid. Thyroid 2005 Oct;15(10):1199-201.

4. Tsang K, Duggan MA. Vascular proliferation of the thyroid. A complication of fine-needle aspiration. Arch Pathol Lab Med 1992 Oct;116(10):1040-2.

5. Datta R, Venkatesh MD, Nilakantan A, Joseph B. Primary cavernous hemangioma of thyroid gland. J Postgrad Med 2008 Apr-Jun;54(2):147-8.

6. Kumar R, Gupta R, Khullar S, Dasan B, Malhotra A. Thyroid haemangioma: A case report with a review of the literature. Clin Nucl Med 200o Oct;25(10):769-1.

7. Memis A, Arkun R, Ustun EE, Kandiloglu G. Magnetic resonance imaging of intramuscular haemangiomas with emphasis on contrast enhancement patterns. Clin Radiol 1996 Mar;51(3):198-204.

\section{Author Contributions}

Devika Gupta - Substantial contributions to conception and design, Acquisition of data, Analysis and interpretation of data, Drafting the article, Revising it critically for important intellectual content, Final approval of the version to be published 
Access PDF of article on other devices other devices

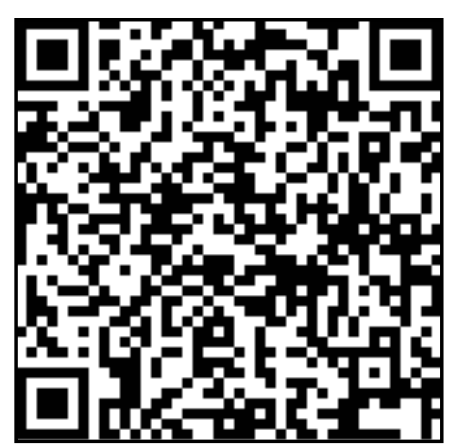

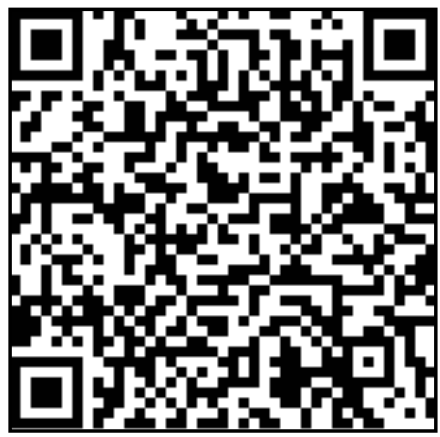

